\title{
C-reactive protein and the metabolic syndrome correlate differently with carotid atherosclerosis between men and women in a Taiwanese community
}

\author{
Pei-Chun Chen ${ }^{\mathrm{a}}$, Kuo-Liong Chien ${ }^{\mathrm{b}, \mathrm{c}}$, Hsiu-Ching $\mathrm{Hsu}^{\mathrm{c}}$, Ta-Chen $\mathrm{Su}^{\mathrm{c}}$, Ching-Wen $\mathrm{Chang}^{\mathrm{a}}$, \\ Fung-Chang Sung ${ }^{\mathrm{a}, \mathrm{b}, \mathrm{d}, *}$, Yuan-Teh Lee ${ }^{\mathrm{b}, \mathrm{c}, *}$ \\ ${ }^{a}$ Institution of Environmental Health, National Taiwan University College of Public Health, Taipei 100, Taiwan \\ ${ }^{\mathrm{b}}$ Institution of Preventive Medicine, National Taiwan University College of Public Health, Taipei 100, Taiwan \\ ${ }^{\mathrm{c}}$ Department of Internal Medicine, National Taiwan University Hospital, Taipei 100, Taiwan \\ ${ }^{\mathrm{d} I n s t i t u t i o n}$ of Environmental Health, China Medical University College of Public Health, Taichung 404, Taiwan
}

Received 10 September 2007; accepted 7 January 2008

\begin{abstract}
Little is known about the role of C-reactive protein (CRP) and metabolic syndrome (MetS) in carotid atherosclerosis among Chinese. In the present cross-sectional study, we examined this relationship and emphasized the sex differences in 456 men and 354 women aged 39 years and older who participated in a community-based cohort study in Taiwan. These participants received measurements for highsensitivity CRP and ultrasound examinations for common carotid artery intima-media thickness (IMT) and extracranial carotid artery plaques. Metabolic syndrome was defined by the US National Cholesterol Education Program Adult Treatment Panel III criteria. The women had higher median CRP (1.3 vs $1.1 \mathrm{mg} / \mathrm{L}$ ) and MetS prevalence than the men (58.8 vs 34.2\%). Thicker IMT was associated with MetS in women (multivariate-adjusted odds ratio [OR], 2.07; 95\% confidence interval, 1.04-4.11) but not in men. Compared with participants with $\mathrm{CRP}<1 \mathrm{mg} / \mathrm{L}$, men with $\mathrm{CRP}>3 \mathrm{mg} / \mathrm{L}$ had an elevated OR with the presence of plaque (OR, 1.99; 95\% confidence interval, $1.10-3.61)$, but not women. Compared with men with CRP $<1 \mathrm{mg} / \mathrm{L}$ and no MetS, individuals with MetS and CRP level $>3 \mathrm{mg} / \mathrm{L}$ were 2.2 times $(P=.046)$ more likely to have artery plaque. In conclusion, thicker IMT is related to MetS in women, whereas the presence of plaque is associated with elevated CRP in men, and this association is enhanced by MetS.
\end{abstract}

(C) 2008 Published by Elsevier Inc.

\section{Introduction}

Common carotid artery (CCA) intima-media thickness (IMT) and carotid plaques assessed by ultrasonography have been used as early markers of preclinical atherosclerosis [1-3] and as predictors of stroke, myocardial infarction, and coronary events $[4,5]$. Lorenz et al $[6]$ have confirmed this

\footnotetext{
* Corresponding authors. Fung-Chang Sung is to be contacted at the Institute of Environmental Health, China Medical University College of Public Health, Taichung 404, Taiwan, Tel.: +886 42203 5740, +886 42205 4070; fax: +886 42201 9901. Yuan-Teh Lee, National Taiwan University College of Medicine and Hospital, Taipei 100, Taiwan. Tel.: +886 22356 2830; fax: +886223959922.

E-mail addresses: fcsung@mail.cmu.edu.tw, fcsung@ntu.edu.tw (F.-C. Sung), ytlee@ntu.edu.tw (Y.-T. Lee).
}

association in a recent meta-analysis study. Epidemiologic studies also have linked C-reactive protein (CRP) in predicting carotid atherosclerosis. An elevated CRP level measured using high-sensitivity assay reflects a low-grade inflammation. The role of inflammation at all stages of the atherosclerosis process has been well established $[7,8]$. Although some studies reported significant relationships between CRP and CCA IMT [9-11], other studies suggested conflicting findings $[12,13]$. Studies also found a positive association between CRP and the presence of carotid plaques, although the correlation was significant only in men $[14,15]$.

An increased level of CRP has been associated with the metabolic syndrome (MetS) and its individual components, a constellation of cardiovascular risk factors $[16,17]$ that may predict IMT thickening and plaques formation $[18,19]$. 
Population-based prospective studies have demonstrated that both CRP and MetS may independently or additively increase the cardiovascular disease (CVD) risk [16,20]. However, whether the presence of MetS influences the relationship between CRP and the preclinical atherosclerosis has not been well established yet. No study has reported for the Chinese population.

We therefore investigated the role of CRP and MetS in the early change of carotid artery wall, assessed by CCA IMT and the presence of plaques, in a community-based study in Taiwan. Whether there are sex differences in the associations was emphasized.

\section{Subjects and methods}

\subsection{Subjects}

Study subjects in this cross-sectional study were participants in the Chin-Shan Community Cardiovascular Cohort study that was established in 1990 to investigate cardiovascular health in a general population of Taiwanese adults. Residents in the community aged 35 years or older identified by household visits were invited to the baseline survey in 1990-1991, excluding those who were very ill or at institutions. A total of 3602 participants (a response rate of $82.8 \%$ ) who consented to participate in this study and were interviewed by trained medical students formed the original cohort. They had no serious illnesses and were able to present at the clinic themselves for a health checkup conducted by cardiologists, regardless if they may later develop events such as stroke, coronary heart disease, cancer, and deaths. The study team subsequently conducted follow-up visits approximately every other year to monitor health status and provided care or consultation for the participants. A detailed description of study design has been reported elsewhere [21].

Carotid ultrasonography was performed at both the second (1994-1995) and fifth (1999-2000) follow-up visits. In this study, blood samples from the second follow-up were mainly used; and those from the fifth follow-up were used as substitutes if specimens from the second visit were not available. Correspondingly, we used ultrasound data measured at the time the participants provided blood samples. Among 1703 subjects with potential specimens for CRP testing, 1318 individuals received ultrasound measurement. We excluded 325 persons with insufficient blood volume for the CRP test, 115 persons presented incomplete information on MetS variables and carotid indices, and 57 individuals presented coronary heart disease or stroke at the time of receiving ultrasound measurements. We also excluded 11 persons with a log-transformed CRP level higher than 3 standard deviations (SDs) in the sex-specific distribution because of suspected inflammation conditions. A subset of 456 men and 354 women aged 39 years or older were included in this study. Compared with the original cohort, the included subjects were older and exhibited more prevalent hypertension and medication for hypertension at the baseline in both sexes. This study was approved by the Institutional Review Board at National Taiwan University Hospital.

\subsection{Laboratory measurements}

Venous blood samples were drawn from participants after a 12-hour overnight fast and transported with an ice bath to the laboratory at National Taiwan University Hospital within 6 hours. Plasma was obtained by centrifugation at $3000 \mathrm{~g}$ for 10 minutes at $4^{\circ} \mathrm{C}$, fractionated into $0.5-\mathrm{mL}$ aliquots with protease inhibitor cocktail (Sigma, Saint Louis. MO), and stored at $-70^{\circ} \mathrm{C}$ until analysis. Samples were thawed and measured in duplicate for CRP levels in the plasma using a high-sensitivity immunoturbidimetric assay (Denka Seiken, Tokyo, Japan) on a Hitachi 911 analyzer (Roche Diagnostics, Indianapolis, IN) [22]. The lowest detectable concentration of high-sensitivity CRP was $0.1 \mathrm{mg} / \mathrm{L}$. Coefficients of variation, within- and between-assay, were $5.6 \%$ and $6.58 \%$, respectively. Serum levels of lipids and fasting glucose were determined as described elsewhere [21,23]. All measurements were performed in a central laboratory at the hospital.

\subsection{Definitions of MetS and other risk factors}

According to the criteria of the US National Cholesterol Education Program Adult Treatment Panel III [24], MetS was defined as the presence of at least 3 of the following 5 components: triglycerides $\geq 150 \mathrm{mg} / \mathrm{dL}(1.7 \mathrm{mmol} / \mathrm{L})$, systolic blood pressure $\geq 130 \mathrm{~mm} \mathrm{Hg}$ or diastolic blood pressure $\geq 85 \mathrm{~mm} \mathrm{Hg}$ or taking antihypertensive drugs, highdensity lipoprotein (HDL) cholesterol $<40 \mathrm{mg} / \mathrm{dL}(1.0$ $\mathrm{mmol} / \mathrm{L})$ in men or $<50 \mathrm{mg} / \mathrm{dL}(1.3 \mathrm{mmol} / \mathrm{L})$ in women, fasting glucose $\geq 110 \mathrm{mg} / \mathrm{dL}(6.1 \mathrm{mmol} / \mathrm{L})$, and waist circumference $\geq 90 \mathrm{~cm}$ in men or $\geq 80 \mathrm{~cm}$ in women (the modified definition of central obesity for Asians) [17]. Individuals with systolic blood pressure higher than $140 \mathrm{~mm}$ $\mathrm{Hg}$ and/or diastolic blood pressure higher than $90 \mathrm{~mm} \mathrm{Hg}$ and/or receiving antihypertensive medication were considered as hypertensive. Diabetes mellitus was defined as a fasting serum glucose level higher than $126 \mathrm{mg} / \mathrm{dL}(7.0$ $\mathrm{mmol} / \mathrm{L}$ ) and/or a history of using hypoglycemic agents or insulin injections.

\subsection{Carotid ultrasonography}

The CCA IMT and carotid plaque quantification were determined using a Hewlett-Packard SONO 1500 (Palo Alto, CA) ultrasound system, equipped with a 7.5-MHz real-time B-mode scanner and a 5.6-MHz pulsed-Doppler mode scanner. The physicians who performed the evaluation were blind to the health status and clinical characteristics of the study subjects. Details on the ultrasonographic methodology have been described previously $[25,26]$. The maximal CCA IMT was measured bilaterally at sites 0 to 10 and 10 to $20 \mathrm{~mm}$ on the CCA distal from the carotid bifurcation. The IMT of the posterior wall of the distal CCA was defined as the distance from the leading edge of the first 
echogenic line (lumen-intima interface) to the leading edge of the second line (media-adventitia interface). The inter- and intraobserver correlation coefficients were 0.86 to 0.93 and 0.70 to 0.87 , respectively, for both sides of the CCA IMT measurements [25]. For statistical analysis, average IMT values of the 4 CCA sites were used, 2 each from the right and the left arteries.

The plaque measurement was performed bilaterally for the following extracranial carotid artery segments: proximal CCA and distal CCA ( $>20$ and $0-20 \mathrm{~mm}$ distal to the bulb bifurcation, respectively), bulb, internal carotid artery, and external carotid artery. Carotid atherosclerotic plaque was defined as a focal structure encroaching into the arterial lumen of at least $0.5 \mathrm{~mm}$ or $50 \%$ of the surrounding IMT, or an intima-media complex thickness $>1.5 \mathrm{~mm}$ [27]. A grade ranging from 0 to 4 was assigned for each segment according to the numbers and sizes of plaques and to the percentage diameter stenosis. Individuals with normal or no observable plaque were given grades of zero. As the degree of luminal stenosis of the internal carotid artery reaches $>50 \%$, the peak systolic velocity increases to $>1.25 \mathrm{~m} / \mathrm{s}$ in addition to the criterion of diameter stenosis. Total plaque score was computed by summing the grades from all chosen segments. The plaque measurement scoring showed good reproducibility with a $\kappa$ value of 0.70 [26].

\subsection{Statistical analysis}

Clinical characteristics were compared between men and women using the Student $t$ test for continuous variables and the $\chi^{2}$ test for categorical variables. For a nonnormal distribution, the difference in medians between the 2 groups was examined using the Wilcoxon rank sums test. In the Framingham population, Rutter et al [20] found that the association between the number of MetS components present and mean CRP levels was stronger in women than in men. Our data analyses assessed associations of CRP, MetS, and the combining effects with carotid indices by sex. We applied the multivariate logistic regression analyses to measure the odds ratio (OR) of thick IMT (CCA IMT $\geq 1 \mathrm{~mm}$ ) [2] and the presence of plaque (plaque score $>0$ ) with 3 models: one by sex-specific CRP quartiles, one by 3 categories of CRP $(<1,1-3$, and $>3 \mathrm{mg} / \mathrm{L})$, and one by MetS (absent and present). The 3 categories of CRP levels were adapted from the recommendation by the US Centers for Disease Control and Prevention and the American Heart Association [8]. Further multivariate logistic analysis examined whether effects of CRP on carotid indices were different between MetS-positive persons and MetS-negative persons by sex using individuals with CRP $<1 \mathrm{mg} / \mathrm{L}$ and MetS negative as the reference group. Test for the trend across CRP categories was performed when it was appropriate in the multiple logistic regression models. The statistical significance level was set at 2 -sided $P<.05$. All analyses were performed using SAS 9.1 (SAS Institute, Cary, NC).

\section{Results}

The mean age was 65.7 years for men and 66.7 years for women $(P=.18)$ (Table 1). Women had higher median CRP value $(1.3 \mathrm{vs} 1.1 \mathrm{mg} / \mathrm{L}, P=.069$ with interquartile range of $0.8-2.5$ vs $0.6-2.1 \mathrm{mg} / \mathrm{L}$ ) and were more prevalent in MetS $(58.8$ vs $34.2 \%, P<.001)$. In men, the most prevalent MetS component was low HDL cholesterol (54.8\%), followed by elevated blood pressure (51.3\%) and impaired fasting glucose $(45.2 \%)$. The ranking order in women was low HDL cholesterol (77.7\%), abdominal obesity (74.3\%), and elevated blood pressure (59.6\%). Compared with women, the cardiovascular risk profiles were favorable in men except that men exhibited much more prevalence in smoking. However, men had thicker average CCA IMT (mean \pm SD, $0.85 \pm 0.29$ vs $0.80 \pm 0.26 \mathrm{~mm} P=.008)$ and presented higher plaque prevalence $(27.4 \%$ vs $23.7 \%, P=.23)$.

Multiple logistic regression analysis for the study participants revealed that, compared with persons with

Table 1

Clinical features and metabolic risk factors of study subjects

\begin{tabular}{|c|c|c|c|c|}
\hline & $\begin{array}{l}\text { All } \\
(\mathrm{n}=810)\end{array}$ & $\begin{array}{l}\text { Men } \\
(n=456)\end{array}$ & $\begin{array}{l}\text { Women } \\
(\mathrm{n}=354)\end{array}$ & $P$ \\
\hline Age (y) & $66.1 \pm 10.9$ & $65.7 \pm 10.9$ & $66.7 \pm 10.9$ & .18 \\
\hline $\operatorname{BMI}\left(\mathrm{kg} / \mathrm{m}^{2}\right)$ & $24.0 \pm 3.4$ & $23.5 \pm 3.3$ & $24.7 \pm 3.5$ & $<.001$ \\
\hline $\begin{array}{l}\text { HDL cholesterol } \\
(\mathrm{mmol} / \mathrm{L})\end{array}$ & $1.05 \pm 0.34$ & $1.04 \pm 0.36$ & $1.06 \pm 0.31$ & .40 \\
\hline $\begin{array}{l}\text { LDL cholesterol } \\
(\mathrm{mmol} / \mathrm{L})\end{array}$ & $3.29 \pm 1.03$ & $3.12 \pm 0.94$ & $3.51 \pm 1.09$ & $<.001$ \\
\hline Current smoking (\%) & 30.2 & 50.6 & 3.7 & $<.001$ \\
\hline Hypertension (\%) & 38.3 & 33.6 & 44.4 & .002 \\
\hline Diabetes mellitus (\%) & 21.7 & 21.7 & 21.8 & .99 \\
\hline \multicolumn{5}{|l|}{ CRP } \\
\hline $\begin{array}{l}\text { Median } \\
\text { (interquartile) } \\
(\mathrm{mg} / \mathrm{L})\end{array}$ & $1.2(0.7-2.4)$ & $1.1(0.6-2.1)$ & $1.3(0.8-2.5)$ & $.069^{\mathrm{a}}$ \\
\hline$<1 \mathrm{mg} / \mathrm{L}(\%)$ & 39.4 & 41.5 & 36.7 & .38 \\
\hline $1-3 \mathrm{mg} / \mathrm{L}(\%)$ & 41.9 & 40.1 & 44.1 & \\
\hline$>3 \mathrm{mg} / \mathrm{L}(\%)$ & 18.8 & 18.4 & 19.2 & \\
\hline MetS (\%) & 44.9 & 34.2 & 58.8 & $<.001$ \\
\hline $\begin{array}{l}\text { Waist girth } \geq 90 \\
\text { in men or } \geq 80 \mathrm{~cm} \\
\text { in women }\end{array}$ & 48.3 & 28.1 & 74.3 & $<.001$ \\
\hline $\begin{array}{l}\text { Triglycerides } \\
\geq 1.7 \mathrm{mmol} / \mathrm{L}\end{array}$ & 23.0 & 21.7 & 24.5 & .34 \\
\hline $\begin{array}{l}\text { HDL cholesterol } \\
<1.0 \text { in men or } \\
<1.3 \mathrm{mmol} / \mathrm{L} \\
\text { in women }\end{array}$ & 64.8 & 54.8 & 77.7 & $<.001$ \\
\hline $\begin{array}{l}\text { Blood pressure } \\
\geq 130 / 85 \mathrm{~mm} \mathrm{Hg} \\
\text { or treatment }\end{array}$ & 54.9 & 51.3 & 59.6 & .019 \\
\hline $\begin{array}{c}\text { Fasting glucose } \\
\geq 6.1 \mathrm{mmol} / \mathrm{L}\end{array}$ & 44.8 & 45.2 & 44.4 & .81 \\
\hline CCA IMT (mm) & $0.83 \pm 0.28$ & $0.85 \pm 0.29$ & $0.80 \pm 0.26$ & .008 \\
\hline $\begin{array}{l}\text { Thicker CCA IMT } \\
(>1 \mathrm{~mm})(\%)\end{array}$ & 20.0 & 21.7 & 17.8 & .17 \\
\hline Plaque presence $(\%)$ & 25.8 & 27.4 & 23.7 & .23 \\
\hline
\end{tabular}

Values are expressed as mean \pm SD unless indicated. a Wilcoxon rank sums test. 
Table 2

Multiple variable-adjusted ORs and 95\% CIs for thicker IMT and plaque presence by CRP categories and MetS

\begin{tabular}{|c|c|c|c|c|c|c|}
\hline & \multicolumn{3}{|c|}{ Thicker IMT } & \multicolumn{3}{|c|}{ Plaque presence } \\
\hline & All & Men & Women & All & Men & Women \\
\hline \multicolumn{7}{|c|}{ Model $1^{\text {a }}$ (for CRP quartile) } \\
\hline Q1 & 1.00 & 1.00 & 1.00 & 1.00 & 1.00 & 1.00 \\
\hline Q2 & $1.04(0.60-1.80)$ & $0.74(0.36-1.52)$ & $0.77(0.32-1.84)$ & $1.20(0.74-1.95)$ & $0.89(0.47-1.67)$ & $0.99(0.46-2.11)$ \\
\hline Q3 & $1.45(0.82-2.56)$ & $1.16(0.57-2.36)$ & $1.38(0.60-3.16)$ & $1.31(0.78-2.21)$ & $1.01(0.52-1.94)$ & $1.35(0.63-2.87)$ \\
\hline Q4 & $1.46(0.84-2.55)$ & $1.54(0.79-3.00)$ & $1.01(0.44-2.34)$ & $1.66(1.00-2.74)$ & $1.82(0.99-3.38)$ & $0.96(0.45-2.06)$ \\
\hline$P$ trend $^{\mathrm{b}}$ & 0.17 & 0.065 & 0.82 & 0.054 & 0.013 & 0.88 \\
\hline \multicolumn{7}{|c|}{ Model $2^{\mathrm{a}}$ (for CRP categories, mg/L) } \\
\hline$<1$ & 1.00 & 1.00 & 1.00 & 1.00 & 1.00 & 1.00 \\
\hline $1-3$ & $1.14(0.75-1.75)$ & $1.13(0.65-1.95)$ & $1.19(0.60-2.40)$ & $1.20(0.82-1.76)$ & $1.30(0.78-2.15)$ & $0.99(0.54-1.83)$ \\
\hline$>3$ & $1.34(0.81-2.23)$ & $1.29(0.67-2.45)$ & $1.49(0.63-3.53)$ & $1.69(1.06-2.69)$ & $1.99(1.10-3.61)$ & $1.11(0.51-2.42)$ \\
\hline$P$ trend $^{\mathrm{b}}$ & 0.28 & 0.48 & 0.38 & 0.029 & 0.029 & 0.76 \\
\hline \multicolumn{7}{|c|}{ Model $3^{c}$ (for MetS) } \\
\hline Absent & 1.00 & 1.00 & 1.00 & 1.00 & 1.00 & 1.00 \\
\hline Present & $1.64(1.08-2.51)$ & $1.34(0.79-2.38)$ & $2.07(1.04-4.11)$ & $1.37(0.93-2.01)$ & $1.32(0.80-2.20)$ & $1.44(0.80-2.61)$ \\
\hline
\end{tabular}

Three models separately estimate ORs associated with CRP quartiles; CRP categories $<1,1$ to 3 , $>3$ mg/L; and the metabolic syndrome.

a Adjusted for age, sex (for all), BMI, smoking, diabetes mellitus, hypertension, HDL cholesterol, and LDL cholesterol.

b $P$ for trend across CRP categories.

c Adjusted for age, sex (for all), BMI, smoking, and LDL cholesterol.

CRP $<1 \mathrm{mg} / \mathrm{L}$, men with CRP $>3 \mathrm{mg} / \mathrm{L}$ had a significant presence of plaque (OR, 1.99; 95\% confidence interval [CI], 1.10-3.61; $P$ for trend $=.029)$ (Table 2). This association was not significant for women $(P$ for trend $=.76)$. The sex disparity remained when CRP levels were categorized into sex-specific quartiles. On the other hand, MetS was significantly associated with thicker IMT but not with the
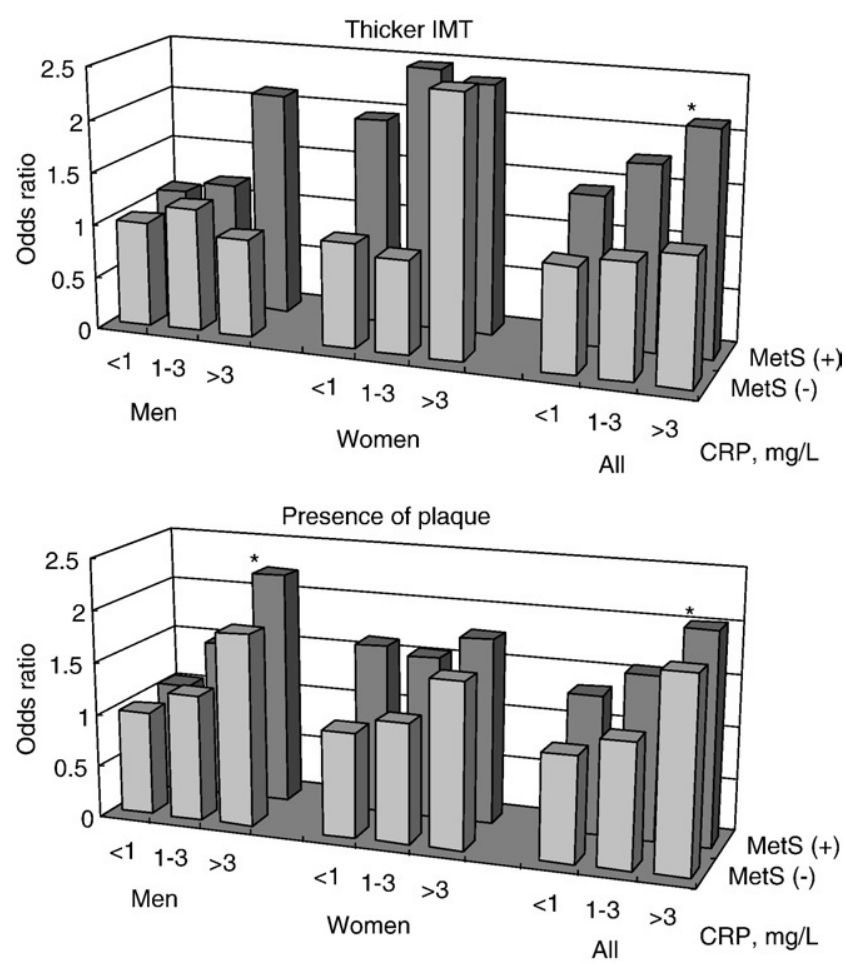

Fig. 1. Multiple-adjusted ORs for thicker common carotid IMT (IMT $\geq 1 \mathrm{~mm}$ ) and presence of plaque by CRP categories and MetS controlling for age, sex (for all), BMI, smoking, and LDL cholesterol. ${ }^{*} P<.05$. presence of plaque. This association was significant in women (OR, 2.07; 95\% CI, 1.04-4.11) but not in men.

Fig. 1 shows the results of logistic regression analyses assessing the interaction between MetS and CRP in the association with thicker IMT and plaque presence. The presence of plaque, instead of thicker IMT, had a doseresponse association with CRP levels in MetS-negative subjects. The risks for both plaque presence and thicker IMT were increased in subjects with MetS, much sharper in women on IMT. Compared with persons with CRP $<1 \mathrm{mg} / \mathrm{L}$ and non-MetS, those with CRP $>3 \mathrm{mg} / \mathrm{L}$ and MetS had the highest ORs of thicker IMT (OR, 2.13; 95\% CI, 1.11-4.09) and presence of plaque (OR, 2.03; 95\% CI, 1.11-3.71). Sexspecific analyses showed that the OR of plaque presence was elevated to 2.22 (95\% CI, 1.01-4.88) in men with higher CRP and MetS, but no significant association was observed in women.

\section{Discussion}

This study revealed factor-specific associations with the indices of early carotid artery alteration for an Asian community population. Metabolic syndrome was more likely related to thicker CCA IMT in women, whereas the elevated CRP level was more likely to have an association with the presence of plaque in men, after controlling for traditional CVD risk factors.

The carotid atherosclerosis phenotypes measured using ultrasound can be used to differentiate atherosclerosis process from the early stage to the advanced stage associated with distinct risk profiles [28,29]. Increased IMT reflects the early changes in the arterial wall associated with injuries from lipids and hypertension [2,29]. When plaque formation occurs, it likely reflects a later atherosclerosis, implicated 
inflammation, oxidation, and smooth muscle cell replication [30]. Consistent with this insight, we observed the plaque presence but not thicker CCA IMT significant at higher CRP profiles. The Framingham study and a Korean study focusing on general populations also showed a lack of association between CRP and CCA IMT in both sexes $[12,13]$.

Our observation did not show a significant association between MetS and the presence of plaque unless the CRP effect was included, in contrast with some previous studies $[18,19]$. The small sample size may be one of the explanations for this result. However, the plaque prevalence in this study was at least $26.4 \%$ in the sex-specific MetS subgroups, higher than the prevalence of thicker CCA IMT (22.1\%) (data not shown). The lack of association between MetS and carotid plaque is unlikely due to the low plaque prevalence and insufficient statistical power. A recent study showed that the CCA IMT thickness instead of the total plaque volume was significantly associated with MetS [31]. Two studies have suggested unequal associations between MetS and carotid atherosclerosis introduced by the elevated blood pressure, a prevalent component of MetS. One study has reported that MetS does not increase the odds of carotid atherosclerosis in subjects without hypertension [32]. The other study found that subjects with both MetS and elevated blood pressure are more likely to have plaque or stenosis than those with MetS alone [33]. Because atherosclerosis is a complex process involving multifactorial etiology, it is possible that a specific MetS component is the major relevance in the carotid atherosclerosis [28,33]. A prospective survey has demonstrated that traditional risk factors such as hypertension and hyperlipidemia are more capable to predict the early carotid atherosclerosis, whereas high fibrinogen, lipoprotein (a), and diabetes were more relevant to the advanced atherosclerosis [28]. Metabolic syndrome alone (presence or not) may not be used as the sole indicator in predicting atherosclerosis.

The strength of this study is the sex-specific assessment for the joint effect of high CRP and MetS on carotid atherosclerosis, which was rarely reported. An elevated level of CRP plus the presence of MetS may better predict the greatest odds of thicker IMT and plaques than does the presence of either one alone. This finding agrees with the Women's Health Study, which demonstrated that the risk of incident CVD is the highest by combining the 2 variables [16]. Our study even showed further that the combined effect strengthens the association between CRP and having plaques, particularly in men. Our analysis also showed that the average CRP level was the highest among persons with MetS and higher body mass index (BMI) and the lowest in persons with no MetS and low BMI (data not shown). A study subject with a higher BMI had a higher CRP level regardless of the MetS status.

The sex difference in the association between CRP and carotid atherosclerosis is controversial. Two studies have shown a positive association between CRP levels and carotid plaque in men $[14,15]$, consistent with this study. This relationship is present only in women, for internal carotid IMT and carotid stenosis, in the Framingham Heart Study [12]. Different carotid indices adapted may limit comparisons among studies. With respect to MetS, our results agree with a previous study, which suggested that the syndrome (National Cholesterol Education Program Adult Treatment Panel III criteria) had a stronger association with early carotid atherosclerosis in women than in men [18]. This association has been linked to the influence of estrogen concentration. Lower estrogen concentration may lead to a higher insulin resistance, which is the most accepted hypothesis of MetS pathophysiology [17,34]. In addition, estrogen replacement therapy has been shown to improve endothelial function and to decrease total cholesterol and low-density lipoprotein (LDL) cholesterol [35]. Few women receive estrogen replacement in Taiwan, although $90.5 \%$ of women were postmenopausal in this study.

There are limitations in this study. First, CCA IMT measured by ultrasound may represent not only early atherosclerosis but also vascular hypertrophy [2]. However, the measurement of CCA IMT is still in widespread use in epidemiologic studies and clinical trials because of its greater reliability than other segments such as internal carotid artery and the strong predictive ability to the occurrence of carotid plaques [3]. Second, the stronger MetS relation to thicker IMT than to the presence of plaque in women might be attributed to the obscurity of plaque, especially the internal carotid of obese women. However, we have included BMI as a covariate in all multivariate analysis. Further analysis by BMI $(>27$ vs $<27$ $\mathrm{kg} / \mathrm{m}^{2}$ by Taiwanese standard) did show that the MetS had a stronger association with the presence of plaque than with thicker IMT. The prevalence gap of plaque between high BMI and low BMI $(10.6 \%, P=.036)$ was somewhat greater than that of thicker IMT between the 2 BMI groups $(8.1 \%, P=.084)$. Third, CRP levels and MetS in early atherosclerosis can be considered as risk markers rather than the causal role in this study because of the crosssectional nature.

In summary, this study shows sex differences in how CRP levels and MetS may predict carotid atherosclerosis. C-reactive protein can be a marker for plaques in men, whereas MetS is more closely related to the thicker CCA IMT than to plaque in women. Metabolic syndrome may add clinical information on CRP for persons with early carotid atherosclerosis, particularly for men. These findings warrant further evaluation of the sex differences in the CRP and MetS association with carotid atherosclerosis.

\section{Acknowledgment}

This study was supported by the National Science Council, Executive Yuan, Taiwan, grant number NSC942314-B-039-006, 2005-2006. 


\section{References}

[1] O'Leary DH, Polak JF, Wolfson Jr SK, Bond MG, Bommer W, Sheth $\mathrm{S}$, et al. Use of sonography to evaluate carotid atherosclerosis in the elderly. The Cardiovascular Health Study. CHS Collaborative Research Group. Stroke 1991;22:1155-63.

[2] Simon A, Gariepy J, Chironi G, Megnien JL, Levenson J. Intimamedia thickness: a new tool for diagnosis and treatment of cardiovascular risk. J Hypertens 2002;20:159-69.

[3] Zureik M, Ducimetiere P, Touboul PJ, Courbon D, Bonithon-Kopp C, Berr $\mathrm{C}$, et al. Common carotid intima-media thickness predicts occurrence of carotid atherosclerotic plaques: longitudinal results from the Aging Vascular Study (EVA) study. Arterioscler Thromb Vasc Biol 2000;20:1622-9.

[4] Bots ML, Hoes AW, Koudstaal PJ, Hofman A, Grobbee DE. Common carotid intima-media thickness and risk of stroke and myocardial infarction: the Rotterdam Study. Circulation 1997;96:1432-7.

[5] Hodis HN, Mack WJ, LaBree L, Selzer RH, Liu CR, Liu CH, et al. The role of carotid arterial intima-media thickness in predicting clinical coronary events. Ann Intern Med 1998;128:262-9.

[6] Lorenz MW, Markus HS, Bots ML, Rosvall M, Sitzer M. Prediction of clinical cardiovascular events with carotid intima-media thickness: a systematic review and meta-analysis. Circulation 2007;115:459-67.

[7] Ross R. Atherosclerosis - an inflammatory disease. N Engl J Med 1999;340:115-26.

[8] Pearson TA, Mensah GA, Alexander RW, Anderson JL, Cannon III RO, Criqui M, et al, Centers for Disease Control and Prevention; American Heart Association. Markers of inflammation and cardiovascular disease: application to clinical and public health practice: a statement for healthcare professionals from the Centers for Disease Control and Prevention and the American Heart Association. Circulation 2003;107:499-511.

[9] Winbeck K, Kukla C, Poppert H, Klingelhofer J, Conrad B, Sander D. Elevated C-reactive protein is associated with an increased intima to media thickness of the common carotid artery. Cerebrovasc Dis 2002; 13:57-63.

[10] Magyar MT, Szikszai Z, Balla J, Valikovics A, Kappelmayer J, Imre S, et al. Early-onset carotid atherosclerosis is associated with increased intima-media thickness and elevated serum levels of inflammatory markers. Stroke 2003;34:58-63.

[11] Hak AE, Stehouwer CD, Bots ML, Polderman KH, Schalkwijk CG, Westendorp IC, et al. Associations of C-reactive protein with measures of obesity, insulin resistance, and subclinical atherosclerosis in healthy, middle-aged women. Arterioscler Thromb Vasc Biol 1999;19:1986-91.

[12] Wang TJ, Nam BH, Wilson PW, Wolf PA, Levy D, Polak JF, et al. Association of C-reactive protein with carotid atherosclerosis in men and women: the Framingham Heart Study. Arterioscler Thromb Vasc Biol 2002;22:1662-7.

[13] Hee Choi S, Chang Kim H, Woo Ahn C, Keun Cho H, Soo Cha B, Chung YS, et al. Is high-sensitivity C-reactive protein associated with carotid atherosclerosis in healthy Koreans? Eur J Cardiovasc Prev Rehabil 2005;12:548-54.

[14] Blackburn R, Giral P, Bruckert E, Andre JM, Gonbert S, Bernard M, et al. Elevated C-reactive protein constitutes an independent predictor of advanced carotid plaques in dyslipidemic subjects. Arterioscler Thromb Vasc Biol 2001;21:1962-8.

[15] Makita S, Nakamura M, Hiramori K. The association of C-reactive protein levels with carotid intima-media complex thickness and plaque formation in the general population. Stroke 2005;36:2138-42.

[16] Ridker PM, Buring JE, Cook NR, Rifai N. C-reactive protein, the metabolic syndrome, and risk of incident cardiovascular events: an 8-year follow-up of 14719 initially healthy American women. Circulation 2003;107:391-7.

[17] Eckel RH, Grundy SM, Zimmet PZ. The metabolic syndrome. Lancet 2005;365:1415-28.
[18] Iglseder B, Cip P, Malaimare L, Ladurner G, Paulweber B. The metabolic syndrome is a stronger risk factor for early carotid atherosclerosis in women than in men. Stroke 2005;36:1212-7.

[19] Ahluwalia N, Drouet L, Ruidavets JB, Perret B, Amar J, Boccalon H, et al. Metabolic syndrome is associated with markers of subclinical atherosclerosis in a French population-based sample. Atherosclerosis 2006; 186:345-53.

[20] Rutter MK, Meigs JB, Sullivan LM, D'Agostino Sr RB, Wilson PW. C-reactive protein, the metabolic syndrome, and prediction of cardiovascular events in the Framingham Offspring Study. Circulation 2004;110:380-5.

[21] Lee YT, Lin RS, Sung FC, Yang CY, Chien KL, Chen WJ, et al. ChinShan Community Cardiovascular Cohort in Taiwan-baseline data and five-year follow-up morbidity and mortality. J Clin Epidemiol 2000; 53:838-46

[22] Vukovich TC, Mustafa S, Rumpold H, Wagner O. Evaluation of a turbidimetric Denka Seiken C-reactive protein assay for cardiovascular risk estimation and conventional inflammation diagnosis. Clin Chem 2003;49:511-2.

[23] Chien KL, Sung FC, Hsu HC, Su TC, Lin RS, Lee YT. Apolipoprotein A-I and B and stroke events in a community-based cohort in Taiwan: report of the Chin-Shan Community Cardiovascular Study. Stroke 2002;33:39-44.

[24] Expert Panel on Detection, Evaluation, and Treatment of High Blood Cholesterol in Adults. Executive summary of the third report of the National Cholesterol Education Program (NCEP) Expert Panel on Detection, Evaluation, and Treatment of High Blood Cholesterol in Adults (Adult Treatment Panel III). JAMA 2001;285:2486-97.

[25] Su TC, Jeng JS, Chien KL, Sung FC, Hsu HC, Lee YT. Hypertension status is the major determinant of carotid atherosclerosis: a communitybased study in Taiwan. Stroke 2001;32:2265-71.

[26] Chen CC, Chung MY, Jeng JS, Yip PK, Hwang BS, Chang YC. A scoring system for evaluation of the extent of extracranial carotid atherosclerosis with B-mode imaging. Acta Neural Sin 1995;4:29-33.

[27] Touboul PJ, Hennerici MG, Meairs S, Adams H, Amarenco P, Desvarieux M, et al. Mannheim carotid intima-media thickness consensus (2004-2006). Cerebrovasc Dis 2007;23:75-80.

[28] Willeit J, Kiechl S, Oberhollenzer F, Rungger G, Egger G, Bonora E, et al. Distinct risk profiles of early and advanced atherosclerosis: prospective results from the Bruneck Study. Arterioscler Thromb Vasc Biol 2000;20:529-37.

[29] Spence JD, Hegele RA. Noninvasive phenotypes of atherosclerosis: similar windows but different views. Stroke 2004;35:649-53.

[30] Hegele RA. The pathogenesis of atherosclerosis. Clin Chim Acta 1996; 246:21-38.

[31] Pollex RL, Al-Shali KZ, House AA, Spence JD, Fenster A, Mamakeesick M, et al. Relationship of the metabolic syndrome to carotid ultrasound traits. Cardiovasc Ultrasound 2006;4:28.

[32] Ishizaka N, Ishizaka Y, Hashimoto H, Toda E, Nagai R, Yamakado M. Metabolic syndrome may not associate with carotid plaque in subjects with optimal, normal, or high-normal blood pressure. Hypertension 2006;48:411-7.

[33] Irace C, Cortese C, Fiaschi E, Carallo C, Sesti G, Farinaro E, et al. Components of the metabolic syndrome and carotid atherosclerosis: role of elevated blood pressure. Hypertension 2005;45:597-601.

[34] Kalish GM, Barrett-Connor E, Laughlin GA, Gulanski BI. Postmenopausal Estrogen/Progestin Intervention Trial. Association of endogenous sex hormones and insulin resistance among postmenopausal women: results from the Postmenopausal Estrogen/Progestin Intervention Trial. J Clin Endocrinol Metab 2003;88: 1646-52.

[35] Higashi Y, Sanada M, Sasaki S, Nakagawa K, Goto C, Matsuura H, et al. Effect of estrogen replacement therapy on endothelial function in peripheral resistance arteries in normotensive and hypertensive postmenopausal women. Hypertension 2001;37:651-7. 